\title{
BC3EE2,9B, a synthetic carbazole derivative, upregulates autophagy and synergistically sensitizes human GBM8901 glioblastoma cells to temozolomide
}

\author{
CHIEN-MIN CHEN ${ }^{1,2,7^{*}}$, JHIH-PU SYU ${ }^{3 *}$, TZONG-DER WAY $^{4}$, LI-JIAU HUANG ${ }^{5}$, \\ SHENG-CHU KUO ${ }^{5}$, CHUNG-TIEN LIN ${ }^{1}$ and CHIH-LI LIN ${ }^{3,6}$
}

\author{
${ }^{1}$ Department and Graduate Institute of Veterinary Medicine and Institute of Veterinary Clinical Science, \\ School of Veterinary Medicine, National Taiwan University, Taipei 10617; ${ }^{2}$ Division of Neurosurgery, \\ Department of Surgery, Changhua Christian Hospital, Changhua 50006; ${ }^{3}$ Institute of Medicine, Chung Shan Medical University, \\ Taichung 402; ${ }^{4}$ Department of Biological Science and Technology, College of Life Sciences, \\ ${ }^{5}$ Graduate Institute of Pharmaceutical Chemistry, College of Pharmacy, China Medical University, Taichung 404; \\ ${ }^{6}$ Department of Medical Research, Chung Shan Medical University Hospital, Taichung 402; \\ ${ }^{7}$ School of Medicine, Kaohsiung Medical University, Kaohsiung 807, Taiwan, R.O.C.
}

Received November 29, 2014; Accepted August 7, 2015

DOI: $10.3892 /$ ijmm.2015.2332

\begin{abstract}
Glioblastoma multiforme (GBM) is the most fatal form of human brain cancer. Although temozolomide (TMZ), an oral alkylating chemotherapeutic agent, improves the survival rate, the prognosis of patients with GBM remains poor. Naturally occurring carbazole alkaloids isolated from curry leaves (Murraya koenigii Spreng.) have been shown to possess a wide range of anticancer properties. However, the effects of carbazole derivatives on glioblastoma cells remain poorly understood. In the present study, anti-glioblastoma profiles of a series of synthetic carbazole derivatives were evaluated in vitro. The most promising derivative in this series was BC3EE2,9B, which showed significant anti-proliferative effects in GBM8401 and GBM8901 cells. BC3EE2,9B also triggered cell-cycle arrest, most prominently at the $\mathrm{G}_{1}$ stage, and suppressed glioblastoma cell invasion and migration. Furthermore, BC3EE2,9B induced autophagy-mediated cell death and synergistically sensitized GBM cells to TMZ cytotoxicity. The possible mechanism underlying BC3EE2,9B-induced autophagy may involve activation
\end{abstract}

Correspondence to: Dr Chih-Li Lin, Institute of Medicine, Chung Shan Medical University, 110 Sec. 1, Jianguo North Road, Taichung 402, Taiwan, R.O.C.

E-mail: dll@csmu.edu.tw

Mr. Chung-Tien Lin, Department and Graduate Institute of Veterinary Medicine and Institute of Veterinary Clinical Science, School of Veterinary Medicine, National Taiwan University, $1 \mathrm{Sec} .4$, Roosevelt Road, Taipei 10617, Taiwan, R.O.C.

E-mail: lillian1109ms@yahoo.com.tw

*Contributed equally

Key words: carbazole, glioblastoma, temozolomide, autophagy, Akt of adenosine monophosphate-activated protein kinase and the attenuation of the Akt and mammalian target of the rapamycin downstream signaling pathway. Taken together, the present results provide molecular evidence for the mode of action governing the ability of BC3EE2,9B to sensitize drug-resistant glioblastoma cells to the chemotherapeutic agent TMZ.

\section{Introduction}

Glioblastoma multiforme (GBM) (World Health Organization grade IV) is the most fatal form of malignant brain cancer in humans and accounts for 12-15\% of all intracranial tumors and $50-60 \%$ of all primary brain tumors $(1,2)$. Treatment usually involves radiotherapy combined with temozolomide (TMZ), a DNA-alkylating agent that mispairs nucleotide bases during DNA replication (3). Although TMZ has been shown to increase the two-year survival rate by suppressing the proliferation of glioblastoma cells and upregulation of apoptotic pathways, the overall prognosis of patients with GBM remains poor (4). To date, $>75 \%$ of patients treated with TMZ succumb within 2 years due to recurrent GBM (5). The development of new combination therapies that increase the sensitivity of TMZ may improve the survival rate of patients with GBM.

Autophagy is a fundamental cellular process responsible for the bulk degradation of cytoplasmic components through an autophagosomal-lysosomal pathway (6). It is generally associated with cell survival or a protective response to stress or inflammation; however, sometimes it promotes cell death depending on specific circumstances (7). Autophagic cell death is regarded as an alternative tumor-suppressing mechanism in chemotherapy-resistant cancers, such as glioblastoma (8-10). The autophagic signaling pathway, comprising PI3K, Akt and mammalian target of rapamycin (mTOR), is an important signaling network involved in cell proliferation, survival and tumorigenesis, and is becoming an important target for treatment 
of several types of cancer (11). mTOR, a downstream effector of Akt, has a well-known critical role in suppressing autophagy by activating the downstream molecule p70S6 kinase (p70S6K). The role of autophagy in oncogenesis and anticancer therapy is contradictory (12). Although certain studies suggest that autophagy, rather than apoptosis, is associated with TMZ-induced chemoresistance in GBM (13), other studies have shown that $\mathrm{TMZ}$ is an effective tumor suppressor by inducing autophagic cell death in tumor cells, particularly in glioblastoma (14).

Carbazole alkaloids, obtained from natural sources, such as the oleoresin of curry leaves (Murraya koenigii Spreng.) (15), and their derivatives from synthesized sources, are well known for their various pharmacological activities, including anti-proliferation (16), anti-angiogenesis and anti-inflammation (17) activities, their ability to inhibit DNA topoisomerase (18), and their ability to sensitize cancer cells to anticancer drugs (19). Previous studies have demonstrated the selective antitumor activity of carbazole in several human cancer cell lines, including lung, colon, liver and leukemia (20). However, the effects of carbazole derivatives on glioblastoma cells remain poorly understood. In our recent study, we proposed a mechanism by which carbazole derivatives effectively trigger cell cycle arrest and programmed cell death in breast cancer cells (20). Carbazole derivatives have also been shown to increase autophagolysosomal membrane permeability, which may resensitize drug-resistant cancer cells to chemotherapeutic agents (21). Therefore, the sensitizing effects of carbazole derivatives may be mediated by the activation of the autophagy signaling pathway.

The aim of the present study was to determine the anti-glioblastoma effects of synthetic carbazole derivatives. In total, 35 different carbazole derivatives were synthesized and their ability to inhibit the proliferation of GBM8401 and GBM8901 cells was measured. Of the derivatives analyzed, bis(carbazole-2,9N-benzyl)-3-ethyl ethanoate (BC3EE2,9B) exhibited the most promising anti-proliferation and autophagic-induced cell death activities. Exposure of GBM8901 and GBM8401 cells to BC3EE2,9B induced autophagy-mediated cell death through suppression of the Akt-mTOR signaling pathway and the cells were synergistically sensitized to TMZ cytotoxicity. The results of the study provide a rationale for the mechanism of action through which BC3EE2,9B, a carbazole derivative, sensitizes drug-resistant glioblastoma cells to the chemotherapeutic agent TMZ.

\section{Materials and methods}

Chemical reagents. TMZ, 4',6-diamidino-2-phenylindole (DAPI), propidiumiodide(PI) and3-(4,5-dimethylthiazol-2-yl)2,5-diphenyltetrazolium bromide (MTT) were purchased from Sigma-Aldrich (München, Germany). Antibodies to $\beta$-actin (\#sc-47778), anti-adenosine monophosphate-activated protein kinase (AMPK; \#sc-25792), anti-p-AMPK (\#sc-33524), and anti-p-mTOR (\#sc-101738) were obtained from Santa Cruz Biotechnology, Inc. (Dallas, TX, USA). Antibodies to anti-p-Akt (\#05-736) and anti-Akt (\#05-591) were obtained from Millipore (Bedford, MA, USA). Anti-LC3 antibodies (\#NB100-2220) were purchased from Novus Biologicals (Littleton, CO, USA). Primary antibodies were used at a dilution of 1:1,000 in 0.1\% Tween-20 and secondary antibodies were used at 1:5,000 dilutions. Acridine orange was obtained from Life Technologies (Rockville, MD, USA). Carbazole derivatives were synthesized in the laboratory of the Graduate Institute of Pharmaceutical Chemistry, College of Pharmacy, China Medical University (Taichung, Taiwan), under the supervision of Dr L.J. Huang. Carbazole derivatives were synthesized and obtained by the laboratory of Dr L.J. Huang.

Cell cultures and cytotoxicity assays. GBM8901 and GBM8401 cells were maintained in RPMI-1640, and SK-N-MC and Detroit 551 cells were maintained in minimum essential medium (MEM), and were routinely tested for mycoplasma or any other bacterial contamination. All the cultures were supplemented with $10 \%$ fetal bovine serum (FBS), penicillin (50 IU/ml) and streptomycin $(50 \mu \mathrm{g} / \mathrm{ml})$, and cells were grown at $37^{\circ} \mathrm{C}$ in a humidified $5 \% \mathrm{CO}_{2}$ atmosphere. Following treatment, cells were treated with MTT $(1 \mathrm{mg} / \mathrm{ml})$ and incubated for $2 \mathrm{~h}$ at $37^{\circ} \mathrm{C}$. Cell viability was measured by the modified MTT assay. Absorbance of the converted dye was measured at a wavelength of $550 \mathrm{~nm}$ with a 96 -well microplate reader.

Flow cytometry assay. For the cell cycle analysis, cells were cultured in $10-\mathrm{cm}$ culture dishes and seeded at $1 \times 10^{6}$ cells/dish. Subsequently, cell pellets were fixed with methanol at $-20^{\circ} \mathrm{C}$ overnight. Following fixation, cell pellets were incubated at $37^{\circ} \mathrm{C}$ for 30 min with $0.5 \%$ Triton X-100 in phosphate-buffered saline (PBS) and $0.5 \mu \mathrm{g} / \mathrm{ml}$ RNase A. Cells were exposed to $1 \mathrm{ml}$ of PI solution $(50 \mu \mathrm{g} / \mathrm{ml})$ for $30 \mathrm{~min}$ on ice. The nuclei were analyzed in an FACScan laser flow cytometer (Becton-Dickinson, San Jose, CA, USA). Data were acquired and analyzed using WinMDI 2.8 software (Scripps Research Insititute, La Jolla, CA, USA).

Cell migration and invasion assay. The cell migration and invasion assays were performed in a 24-well Boyden chamber with an $8-\mu \mathrm{m}$ pore size polycarbonate membrane (Corning, Inc., Corning, NY, USA). For the migration assay, $1 \times 10^{5}$ cells in $200 \mu \mathrm{l}$ of serum-free medium were added to the upper compartment of the chamber; the lower compartment was filled with $600 \mu \mathrm{l}$ of RPMI-1640 supplemented with $10 \%$ FBS. After incubation at $37^{\circ} \mathrm{C}$ for $24 \mathrm{~h}$, cells remaining in the upper chamber were removed using swabs. The cells on the lower surface of the membrane were fixed with methanol and stained with $0.1 \%$ crystal violet. Images were captured and the cells were counted using a light microscope. The invasion assay was performed using the same procedure, except that the membrane was coated with Matrigel (BD Biosciences, Franklin Lakes, NJ, USA) to form a matrix barrier and $3 \times 10^{4}$ GBM8901 cells were added to the upper compartment of the chamber.

TUNEL assay. GBM8901 cells were seeded in 24-well plates, exposed for $48 \mathrm{~h}$ to microglial-conditioned medium, incubated for $48 \mathrm{~h}$ with either protein samples or a control solution, fixed in $4 \%$ paraformaldehyde for $30 \mathrm{~min}$ at $37^{\circ} \mathrm{C}$ and subsequently treated with DNase for $15 \mathrm{~min}$. The TUNEL assay (Invitrogen, Carlsbad, CA, USA) was performed according to the manufacturer's instructions.

Immunofluorescence and acridine-orange staining assay. For the immunofluorescence assay, cells were cultured on coated slides and treated for $24 \mathrm{~h}$. Following treatment, cells were 

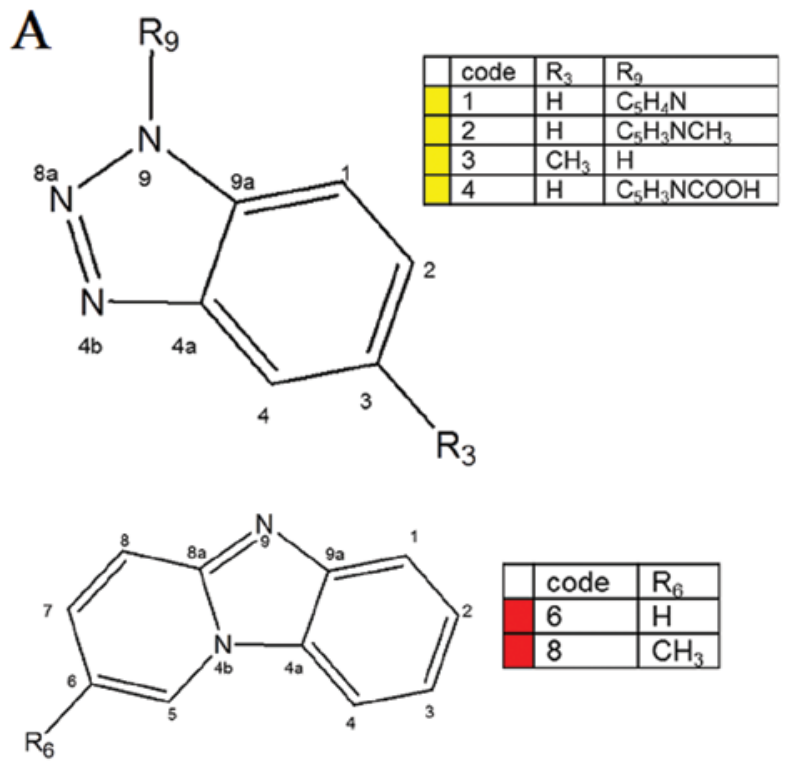<smiles>[R]c1cc2c3ccccc3n([R])c2c[n+]1[R]</smiles>

\begin{tabular}{|l|l|l|l|l|}
\hline code & $\mathrm{R}_{3}$ & $\mathrm{R}_{6}$ & $\mathrm{R}_{9}$ \\
\hline 7 & $\mathrm{H}$ & $\mathrm{CH}_{3}$ & $\mathrm{H}$ \\
\hline 9 & $\mathrm{H}$ & $\mathrm{COOH}$ & $\mathrm{H}$ \\
\hline 10 & $\mathrm{CH}_{3} \mathrm{CO}$ & $\mathrm{H}$ & $\mathrm{H}$ \\
\hline 11 & $\mathrm{H}$ & $\mathrm{CH}_{3}$ & $\mathrm{CH}_{2} \mathrm{C}_{0} \mathrm{H}_{5}$ \\
\hline 18 & $\mathrm{CH}_{2} \mathrm{CHO}$ & $\mathrm{CH}_{3}$ & $\mathrm{H}$ \\
\hline 19 & $\mathrm{CH}_{2} \mathrm{CHO}$ & $\mathrm{H}$ & $\mathrm{CH}_{2} \mathrm{C}_{6} \mathrm{H}_{5}$ \\
\hline 20 & $\mathrm{CH}_{2} \mathrm{CHO}$ & $\mathrm{H}$ & $\mathrm{CH}_{2} \mathrm{C}_{6} \mathrm{H}_{5}$ \\
\hline 21 & $\mathrm{CH}_{2} \mathrm{CHO}$ & $\mathrm{H}$ & $\mathrm{CH}_{2} \mathrm{C}_{6} \mathrm{H}_{2}\left(\mathrm{OCH}_{3}\right)_{3}$ \\
\hline 22 & $\mathrm{H}$ & $\mathrm{H}$ & $\mathrm{CH}_{2} \mathrm{C}_{6} \mathrm{H}_{5}$ \\
\hline 23 & $\mathrm{H}$ & $\mathrm{H}$ & $\mathrm{CH}_{2} \mathrm{C}_{6} \mathrm{H}_{2}\left(\mathrm{OCH}_{3}\right)_{3}$ \\
\hline 24 & $\mathrm{H}$ & $\mathrm{H}$ & $\mathrm{CH}_{2} \mathrm{C}_{5} \mathrm{H}_{4} \mathrm{~N}$ \\
\hline 25 & $\mathrm{H}$ & $\mathrm{H}$ & $\mathrm{CH}_{2} \mathrm{C}_{5} \mathrm{H}_{4} \mathrm{~N}$ \\
\hline 26 & $\mathrm{CHO}$ & $\mathrm{H}$ & $\mathrm{H}$ \\
\hline 27 & $\mathrm{H}$ & $\mathrm{H}$ & $\mathrm{CH}_{2} \mathrm{C}_{5} \mathrm{H}_{4} \mathrm{~N}$ \\
\hline 28 & $\mathrm{CH}_{3}$ & $\mathrm{H}$ & $\mathrm{CH}_{2} \mathrm{C}_{6} \mathrm{H}_{2}(\mathrm{OMe})_{3}$ \\
\hline 29 & $\mathrm{CH}_{3}$ & $\mathrm{H}$ & $\mathrm{H}$ \\
\hline 30 & $\mathrm{CH}_{3}$ & $\mathrm{H}$ & $\mathrm{CH}_{2} \mathrm{C}_{6} \mathrm{H}_{5}$ \\
\hline 31 & $\mathrm{CH}_{3}$ & $\mathrm{H}$ & $\mathrm{CH}_{2} \mathrm{C}_{6} \mathrm{H}_{2}(\mathrm{OMe})_{3}$ \\
\hline 32 & $\mathrm{CH}_{3} \mathrm{C}(=\mathrm{NOH})$ & $\mathrm{H}$ & $\mathrm{H}$ \\
\hline 33 & $\mathrm{CH}_{3} \mathrm{C}(=\mathrm{NOH})$ & $\mathrm{H}$ & $\mathrm{CH}_{2} \mathrm{C}_{6} \mathrm{H}_{2}(\mathrm{OMe})_{3}$ \\
\hline 34 & $\mathrm{COOH}$ & $\mathrm{H}$ & $\mathrm{H}$ \\
\hline 35 & $\mathrm{CH}(\mathrm{OH}) \mathrm{CH}_{3}$ & $\mathrm{H}$ & $\mathrm{H}$ \\
\hline
\end{tabular}

B

\begin{tabular}{|l|l|l|l|l|}
\hline & code & $\mathrm{R}_{6}$ & $\mathrm{R}_{7}$ & $\mathrm{R}_{9}$ \\
\hline 12 & $\mathrm{COOC}_{2} \mathrm{H}_{5}$ & - & $\mathrm{H}$ \\
\hline 13 & $\mathrm{CH}_{2} \mathrm{OH}$ & - & $\mathrm{H}$ \\
\hline 14 & $\mathrm{COOC} \mathrm{H}_{5}$ & - & $\mathrm{CH}_{2} \mathrm{C}_{6} \mathrm{H}_{5}$ \\
\hline 15 & $\mathrm{CH} 2 \mathrm{OH}$ & - & $\mathrm{CH}_{2} \mathrm{C}_{6} \mathrm{H}_{5}$ \\
\hline 16 & $\mathrm{COOCH} \mathrm{C}_{6} \mathrm{H}_{5}$ & - & $\mathrm{CH}_{2} \mathrm{C}_{6} \mathrm{H}_{5}$ \\
\hline 17 & $\mathrm{COOC}_{2} \mathrm{H}_{5}$ & $\mathrm{CH}_{2} \mathrm{C}_{6} \mathrm{H}_{5}$ & $\mathrm{CH}_{2} \mathrm{C}_{6} \mathrm{H}_{5}$ \\
\hline
\end{tabular}

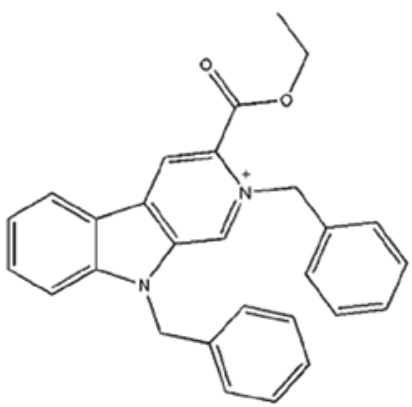

Figure 1. Chemical structures of the (A) 35 selected carbazole derivatives and (B) bis(carbazole-2,9N-benzyl)-3-ethyl ethanoate (BC3EE2,9B).

fixed with $2 \%$ buffered paraformaldehyde, permeabilized in $0.25 \%$ Triton $\mathrm{X}-100$ for $5 \mathrm{~min}$ at $4^{\circ} \mathrm{C}$, and gently agitated in the presence of anti-LC 3 at $4^{\circ} \mathrm{C}$ overnight. Subsequently, the slides were incubated with an fluorescein isothiocyanate-labeled secondary antibody, depending on the origin of the primary antibody, and 4',6-diamidino-2-phenylindole. For the acridine-orange assay, cells were cultured on coated slides and treated for $24 \mathrm{~h}$. Following treatment, cells were exposed to acridine orange solution $(10 \mu \mathrm{g} / \mathrm{ml})$ in PBS for $5 \mathrm{~min}$ and green fluorescence was detected using a fluorescence microscope (DP80/BX53; Olympus, Tokyo, Japan).

Western blot analysis. GBM8901 cells were harvested and homogenized in lysis buffer [50 mM Tris- $\mathrm{HCl}(\mathrm{pH} 8.0)$, $5 \mathrm{mM}$ EDTA, $150 \mathrm{mM} \mathrm{NaCl}, 0.5 \%$ Nonidet P-40, $0.5 \mathrm{mM}$ phenylmethylsulfonyl fluoride and $0.5 \mathrm{mM}$ dithiothreitol] for $30 \mathrm{~min}$ at $4^{\circ} \mathrm{C}$. Equal amounts of total cellular proteins $(50 \mu \mathrm{g})$ were resolved by sodium dodecyl sulfate-polyacrylamide gel electrophoresis (SDS-PAGE), transferred onto polyvinylidene difluoride membranes (Millipore) and probed using primary antibodies, followed by horseradish peroxidase-conjugated secondary antibodies. The immunocomplexes were visualized using an enhanced chemiluminescence kit (Millipore).
Plasmid transfection. DN-AKT and CE-AKT plasmids were obtained from Santa Cruz Biotechnology, Inc. Cells were transfected with transfection reagent Lipofectamine ${ }^{\mathrm{TM}} 2000$ and incubated for $6 \mathrm{~h}$. RPMI-1640 was used instead of Opti-MEM.

Statistical analysis. Statistical comparisons of differences between groups were conducted using the Student's t-test. $\mathrm{P} \leq 0.05$ was considered to indicate a statistically significant difference. All the statistical analyses were performed with the statistical package SPSS for Windows (version 16.0; SPSS, Inc., Chicago, IL, USA).

\section{Results}

Anti-proliferative activity of carbazole derivatives in GBM8901 and GBM8401 cells. To date, only a few carbazole derivatives have been shown to have antitumor activity (23). In the present study, 35 carbazole derivatives were designed and synthesized, and the anti-proliferation activity of each derivative was tested in two human glioblastoma multiforme cell lines, GBM8901 and GBM8401 (Fig. 1A). Five of the synthetic carbazole derivatives (nos. 17, 21, 28, 31 and 33) significantly reduced the growth of glioblastoma cells at a concentration of $10 \mu \mathrm{M}$ (Fig. 2A). Of those 

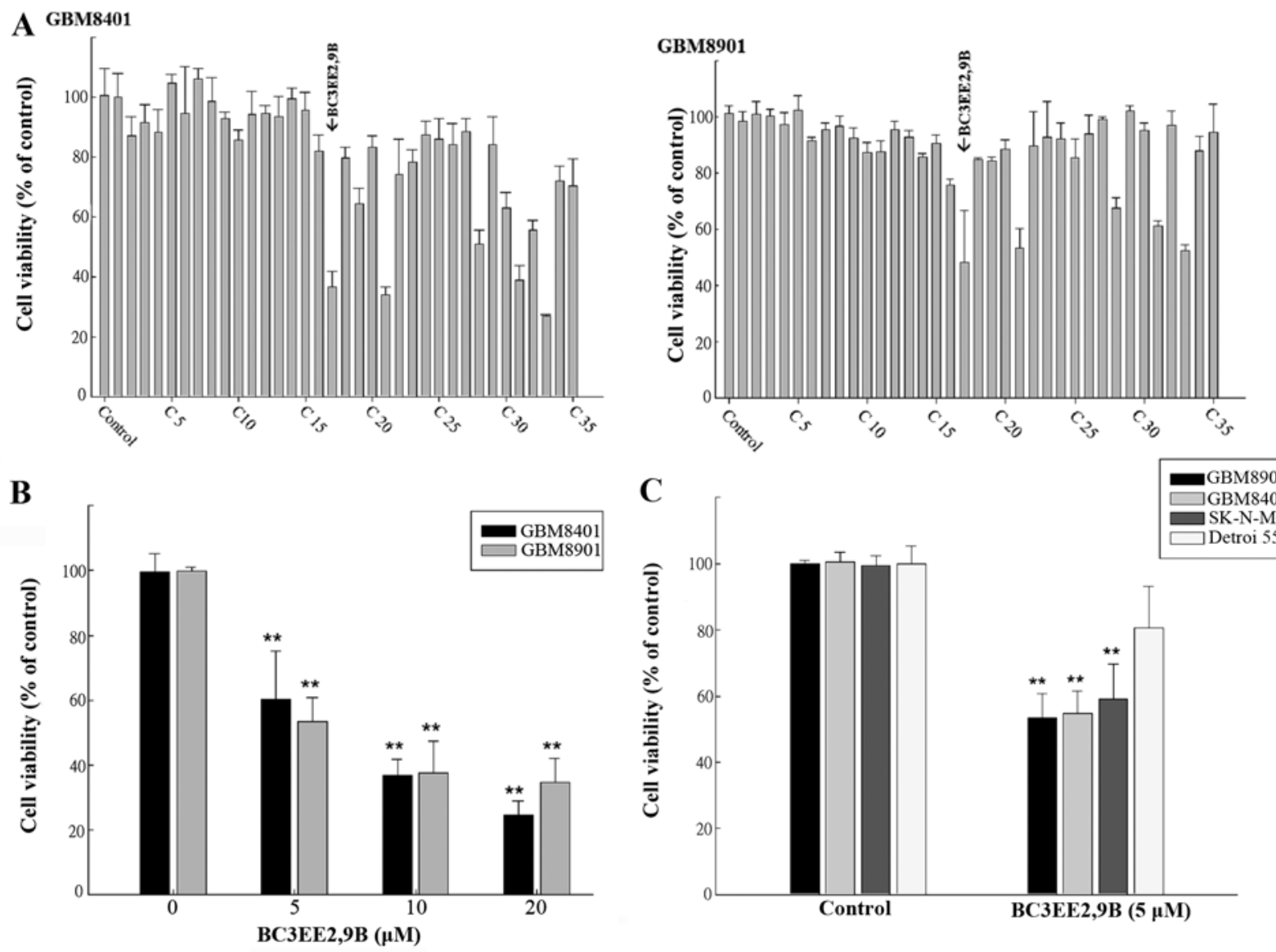

Figure 2. Carbazole derivatives have cytotoxic effects on glioblastoma cells. (A) The cytotoxic potential of the 35 carbazole derivatives. Glioblastoma multiforme (GBM)8401 and GBM8901 cells were incubated with $10 \mu \mathrm{M}$ of carbazole derivatives for $24 \mathrm{~h}$. Cytotoxicity was measured using the MTT assay, and the values are represented as means \pm standard error of the mean of triplicate experiments. (B) Bis(carbazole-2,9N-benzyl)-3-ethyl ethanoate (BC3EE2,9B) exerted cytotoxicity in GBM8401 and GBM8901 cells in a dose-dependent manner. (C) BC3EE2,9B exerted cytotoxicity in cancer cells with only a limited effect in Dettori 551 human normal skin fibroblasts at a concentration of $5 \mu \mathrm{M} .{ }^{* *} \mathrm{P}<0.01$ compared with the non-treated control groups.

derivatives, BC3EE2,9B (no. 17) (Fig. 1B) had the most significant anti-proliferative effect. Viability, as a percent of control, of the GBM8901 cells was $48.13 \pm 18.6 \%$ and that of GBM8401 cells was $36.74 \pm 4.95 \%$ following exposure to BC3EE2,9B (Fig. 2A). Therefore, BC3EE2,9B was used as the primary carbazole derivative in the following experiments. To further determine the inhibitory effect of BC3EE2,9B on glioblastoma cells, a dose-range experiment was performed by treating cells with various concentrations of BC3EE2,9B for $24 \mathrm{~h}$. The inhibitory effects of $\mathrm{BC} 3 \mathrm{EE} 2,9 \mathrm{~B}$ were significant at concentrations ranging from 5 to $20 \mu \mathrm{M}$ in GBM8401 ( $\left.\mathrm{IC}_{50}=7 \mu \mathrm{M}\right)$ and GBM8901 $\left(\mathrm{IC}_{50}=5 \mu \mathrm{M}\right)$ cells (Fig. 2B). To establish whether BC3EE2,9B is toxic to malignant tumor cells, various cell lines, including the human neuroblastoma cell line SK-N-MC and the normal skin cell line Detroit 551, were treated with $5 \mu \mathrm{M}$ BC3EE2,9B for $24 \mathrm{~h}$. BC3EE2,9B treatments significantly inhibited growth of GBM8901, GBM8401 and SK-N-MC cells, however, Detroit 551 cells at $5 \mu \mathrm{M}$ were not significantly inhibited (Fig. 2C). These results show that $\mathrm{BC} 3 \mathrm{EE} 2,9 \mathrm{~B}$ suppresses the proliferation of glioblastoma cells but not healthy cells.

Combination of BC3EE2,9B and TMZ synergistically increases GBM8901 cell death. Studies have shown that treatment of glioblastoma cells with TMZ is associated with concentration-limiting toxicity. In our previous experiment,
BC3EE2,9B was relatively nontoxic to normal cells. The present study aimed to improve the cytotoxic efficacy of TMZ by reducing its concentration in the presence of $\mathrm{BC} 3 \mathrm{EE} 2,9 \mathrm{~B}$. First, a dose-range experiment was performed by treating glioblastoma cells with various concentrations of TMZ alone. A high concentration of TMZ inhibited the proliferation of GBM8901 $\left(\mathrm{IC}_{50}, \sim 800 \mu \mathrm{M}\right)$ and GBM8401 $\left(\mathrm{IC}_{50}, \sim 600 \mu \mathrm{M}\right)$ cells after $24 \mathrm{~h}$ treatment (Fig. 3A). This indicates that TMZ at a high concentration inhibited growth on glioblastoma cells, particularly the GBM8901 cell line. Therefore, the GBM8901 cell line was used in the following experiments. Our previous data showed that BC3EE2,9B exhibits inhibitory activity against glioblastoma cells; therefore, we hypothesized that combining this compound with TMZ will increase the anti-proliferative effect. As shown in Fig. 3B, BC3EE2,9B (5 $\mu \mathrm{M})$ combined with TMZ $(100 \mu \mathrm{M})$ significantly inhibited GBM8901 cell growth for $\leq 72 \mathrm{~h}$ in a dose-dependent manner (Fig. 3C). To further assess whether the two compounds have synergistic benefits on growth inhibition of glioblastoma cells, an isobologram curve was plotted (Fig. 3D). The data demonstrated a strong synergistic effect (confidence interval $<1$ ) among three different ratios (TMZ:BC3EE2,9B, 750:2.5, 100:5 and 200:10, respectively) at $5 \mu \mathrm{M}$ BC3EE2,9B combined with $100 \mu \mathrm{M}$ TMZ. These results show that GBM8901 cells were more sensitive to combined treatment with BC3EE2,9B and TMZ. 

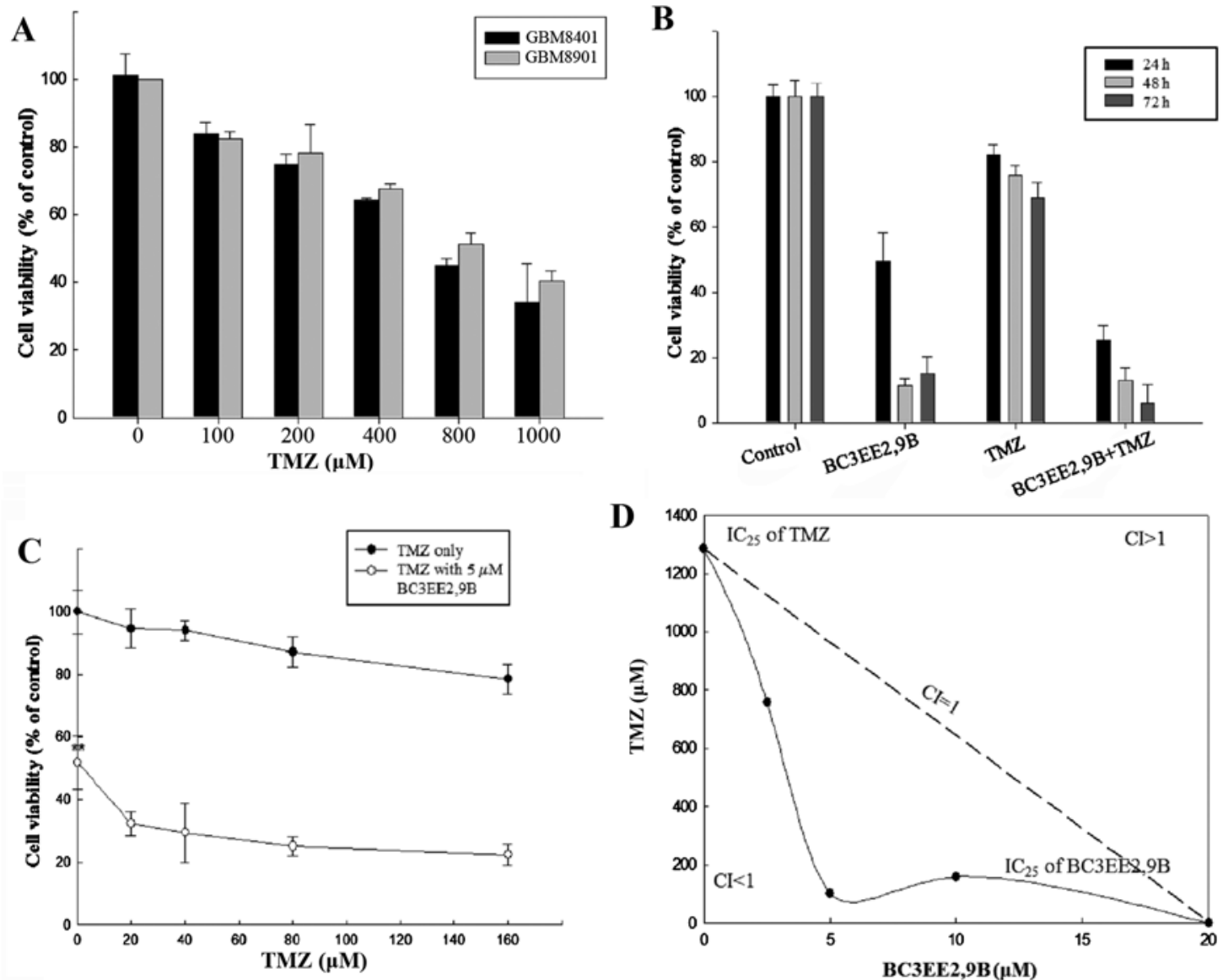

Figure 3. Synergistic activity of bis(carbazole-2,9N-benzyl)-3-ethyl ethanoate (BC3EE2,9B) and temozolomide (TMZ) in glioblastoma cells. (A) The cytotoxicity effects in glioblastoma multiforme (GBM)8401 and GBM8901 cells of various concentrations of TMZ after $24 \mathrm{~h}$ treatment. (B) BC3EE2,9B combined with TMZ significantly inhibited GBM8901 cancer cell viability in a time- and dose-dependent manner. (C) BC3EE2,9B combined with doses $\leq 160 \mu \mathrm{M}$ of TMZ. Viability (as a percentage of controls) of cancer cells treated with BC3EE2,9B combined with TMZ was $\sim 20 \%$ lower compared with the viability of cancer cells treated with either BC3EE2,9B or TMZ alone. (D) The synergistic anticancer effect of the two agents was clearly demonstrated by isobologram analysis shown for the $\mathrm{IC}_{25}$ doses. Bars depict mean \pm standard error of the mean of at least three experiments. A statistically significant difference from the control group, ${ }^{*} \mathrm{P}<0.05$ and $^{* *} \mathrm{P}<0.01$, respectively.

Effects of BC3EE2,9B on GBM8901 cell morphology, cell cycle and migration/invasion. Microscopic analysis revealed that GBM8901 cells exposed to $5 \mu \mathrm{M}$ BC3EE2,9B for $24 \mathrm{~h}$ showed more evidence of cell shrinkage and detachment from culture plates, as well as more cytoplasmic vacuoles compared with the untreated cells (Fig. 4A). By contrast, no clear morphological changes were observed in cells treated with $100 \mu \mathrm{M}$ of TMZ. These results suggest that BC3EE2,9B induces cell death in glioblastoma. To further analyze the nature of cell death, flow cytometric analysis was performed in GBM8901 cells following exposure to BC3EE2,9B with or without TMZ for $24 \mathrm{~h}$ (Fig. 4B). The results showed that $5 \mu \mathrm{M}$ BC3EE2,9B combined with $100 \mu \mathrm{M}$ TMZ slightly induced $\mathrm{G}_{1}$ arrest $(8.65 \%)$; however, no significant sub- $\mathrm{G}_{1}$ hypoploid cell population was observed, indicating that apoptosis may not be the mechanism governing cell death. As motility and metastatic spread are well-known hallmarks of all malignant tumors, particularly glioblastoma, wound healing assays were performed to verify the effects of BC3EE2,9B on migration and invasion of GBM8901 glioblastoma cells. Cells were allowed to grow to confluence, and were scratched to create a cleared area within the monolayer. Following treatments, the movement of glioblastoma cells was imaged and quantified by measuring the migration distance at different time points and comparing it with the front area at time zero. Even a low concentration of BC3EE2,9B $(2.5 \mu \mathrm{M})$ combined with TMZ treatment significantly inhibited cell migration at $72 \mathrm{~h}$ (68.81 $\pm 5.71 \%$ ) (Fig. 4C). Subsequently, a Transwell assay was employed to further measure the effects of BC3EE2,9B on the migratory and invasive capacities of glioblastoma cells. BC3EE2,9B $(2.5 \mu \mathrm{M})$ alone and combined with TMZ $(100 \mu \mathrm{M})$ markedly suppressed the migration of GBM8901 cells (Fig. 4D). As cell migration is believed to be a fundamental step in tumor invasion, the effect of chrysin on the invasive capacity of GBM8901 cells was examined. Treatment of Matrigel-coated wells with BC3EE2,9B $(2.5 \mu \mathrm{M})$ or combined with TMZ $(100 \mu \mathrm{M})$ significantly reduced cell invasion. In particular, the number of invasive GBM8901 cells in cultures exposed to BC3EE2,9B and TMZ decreased by $91.98 \pm 1.07 \%$ relative to the number of cells treated with TMZ alone. These findings suggest that low levels of BC3EE2,9B combined with TMZ effectively stimulate cell death via a non-apoptotic mechanism.

BC3EE2,9B combined with TMZ induces autophagy, but not apoptosis, in GBM8901 cells. Our previous results indicated 

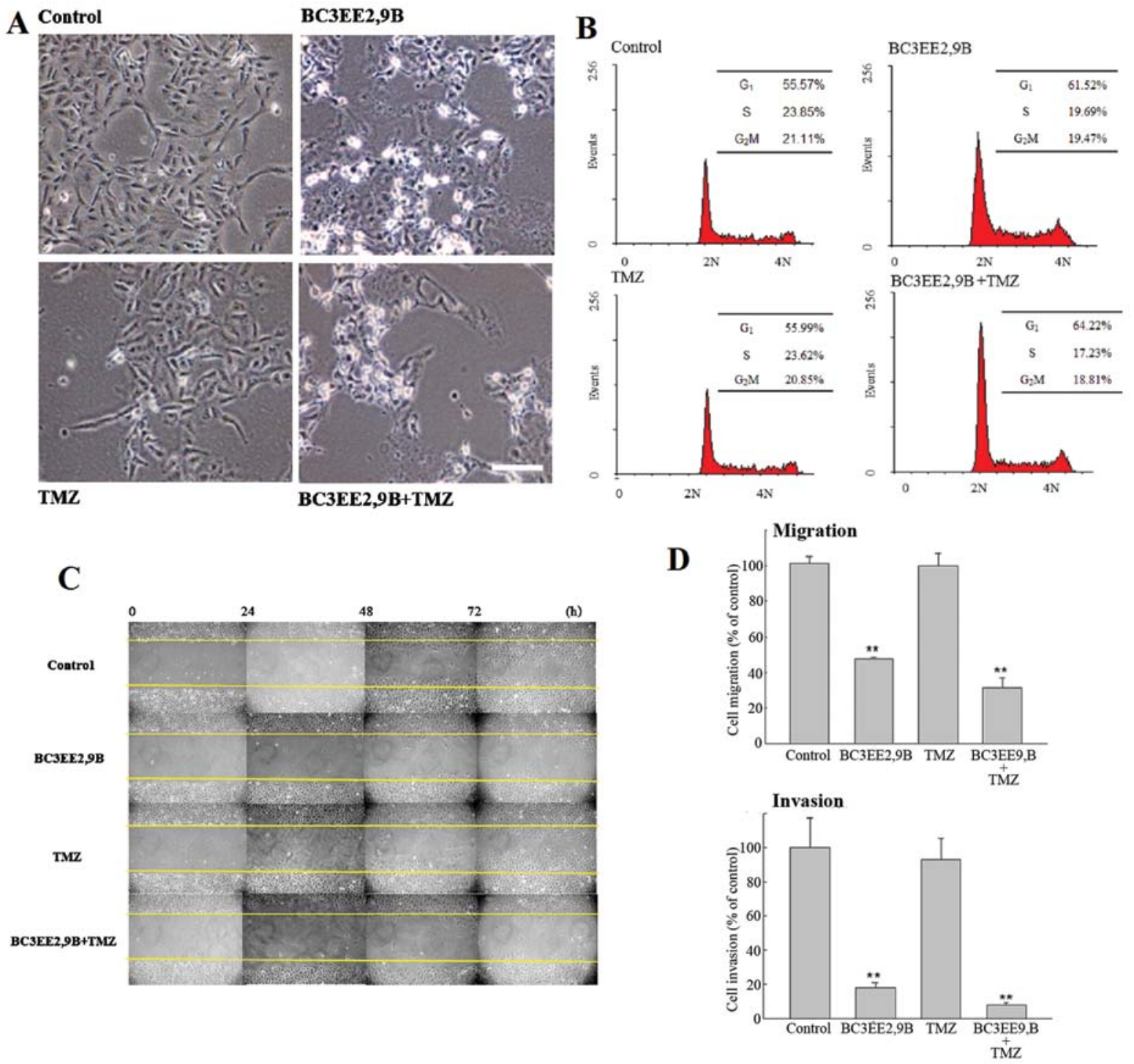

Figure 4. Inhibitory effect of bis(carbazole-2,9N-benzyl)-3-ethyl ethanoate (BC3EE2,9B) and temozolomide (TMZ) on glioblastoma multiforme (GBM)8901 cancer cell morphology, cell cycle and migration and invasion ability. (A) Microscopic assay showed that BC3EE2,9B causes cell shrinkage, detachment from culture plates and a significant number of cytoplasmic vacuoles in GBM8901 cells. (B) Flow cytometry with propidium iodide (PI) staining. No significant sub- $\mathrm{G}_{1}$ hypoploid cell populations were observed in cells treated with BC3EE2,9B and TMZ. Migration and invasion ability, as measured by (C) wound assay or (D) Boyden chamber assay. Data depict mean \pm standard error of the mean of at least three experiments. A statistically significant difference from control group, ${ }^{* *} \mathrm{P}<0.01$. Scale bar represents $100 \mu \mathrm{M}$.

that treatment of GBM8901 cells with BC3EE2,9B results in cell death via a non-apoptotic mechanism. Therefore, the TUNEL assay was used to confirm these finding (Fig. 5A). No TUNEL-positive cells were detected after $24 \mathrm{~h}$ of BC3EE2,9B treatment. Notably however, another carbazole derivative, ac-6K-9TriMoB (no. 21), significantly induced apoptosis. These findings confirmed that cell death due to BC3EE2,9B combined with TMZ is not governed by an apoptotic pathway. A previous study reported that TMZ can induce autophagic cell death in malignant glioblastoma cells (14). Therefore, whether BC3EE2,9B combined with TMZ treatment also induces autophagic cell death was examined. Cells showed an increase in orange fluorescence, indicating the accumulation of acridine orange in the acidic compartments of TMZ-treated cells after exposure to BC3EE2,9B for $24 \mathrm{~h}$ (Fig. 5B). However, treatment with $\alpha c-6 \mathrm{~K}-9$ TriMoB resulted in significantly less orange fluorescence. Furthermore, cells treated with combination therapy showed the presence of LC3-II aggregation, a specific marker associated with autophagosome formation (Fig. 5C). These results indicate that the combination of $\mathrm{BC} 3 \mathrm{EE} 2,9 \mathrm{~B}$ with TMZ induces autophagy, but not apoptosis, in GBM8901 cells.

BC3EE2,9B combined with TMZ enhances autophagy through inactivation of the Akt-mTOR pathway in GBM8901 cells. The detection of LC3-I to LC3-II conversion is a useful and sensitive marker of autophagy (22). Western immunoblotting was performed to probe for LC3. BC3EE2,9B combined with TMZ resulted in a significant increase in the LC3-II level after $24 \mathrm{~h}$ (Fig. 6A); however, $\alpha \mathrm{c}-6 \mathrm{~K}-9$ TriMoB treatment did not lead to an increase in LC3-II level. It is well-known that inhibition of Akt and its downstream target mTOR initiates autophagy. As autophagy is negatively regulated by the PI3K-Akt-mTOR pathway, interference with this pathway promotes autophagy. To elucidate whether BC3EE2,9B 


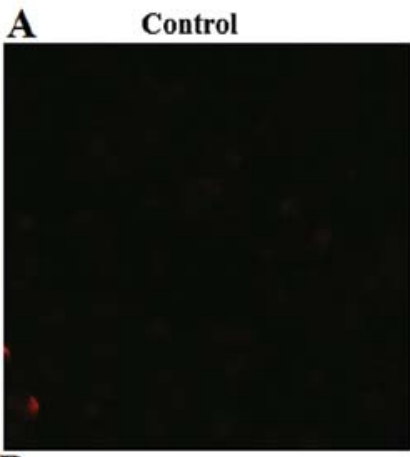

$\mathbf{B}$

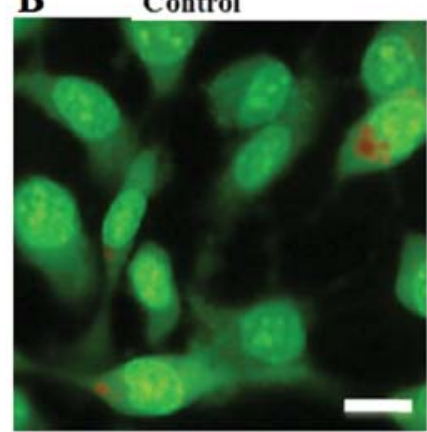

C BC3EE2,9B+TMZ

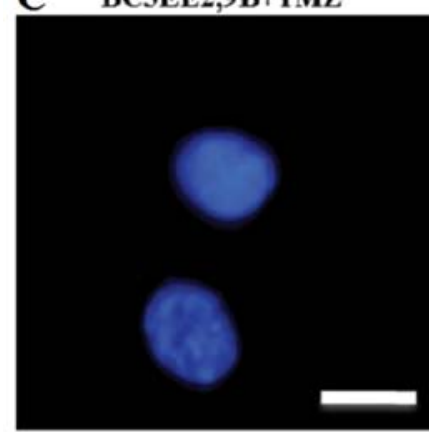

DAPI
BC3EE2,9B+TMZ

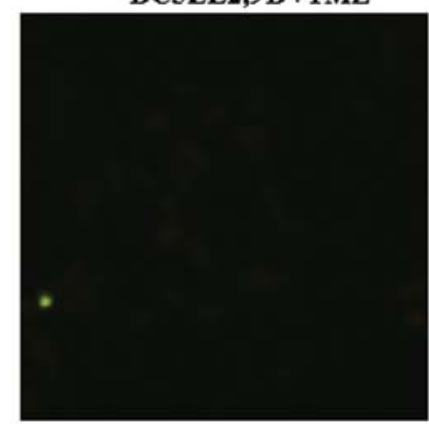

BC3EE2,9B + TMZ
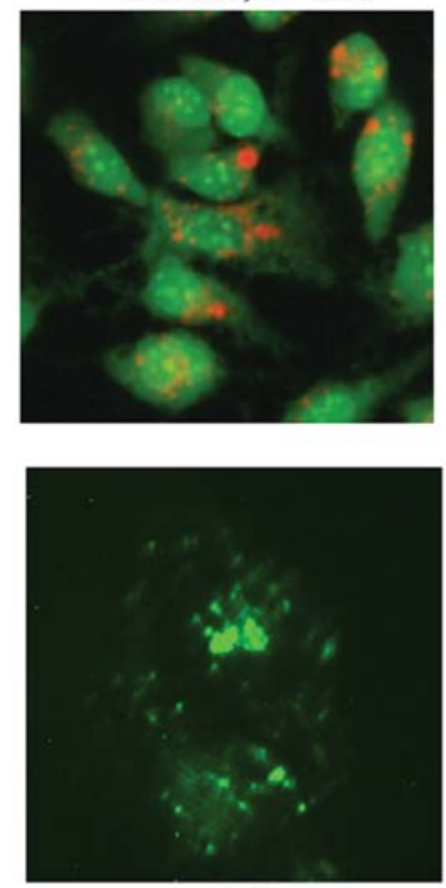

LC3
ac-6K-9TriMoB

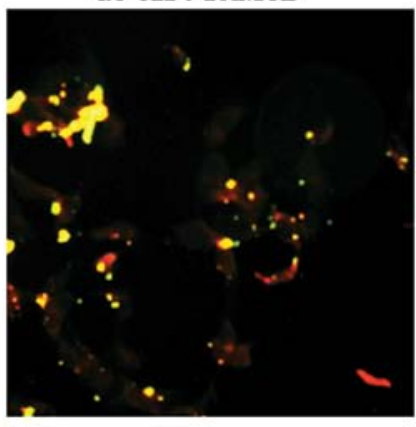

ac-6K-9TriMoB
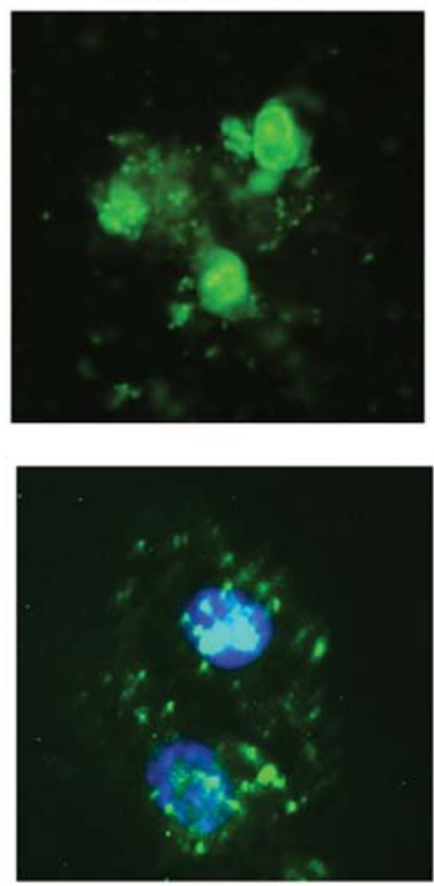

Merged

Figure 5. Combination of bis(carbazole-2,9N-benzyl)-3-ethyl ethanoate (BC3EE2,9B) and temozolomide (TMZ) induced autophagy, but not apoptosis, in glioblastoma multiforme (GBM)8901 cells. (A) Cell apoptosis was measured by the TUNEL assay and fluorescence microscopy. GBM8901 cells were treated with $\alpha \mathrm{c}-6 \mathrm{~K}-9 \mathrm{TriMoB}$ or TMZ combined with BC3EE2,9B for $24 \mathrm{~h}$. (B) Fluorescence microscopy analysis of GBM8901 cells treated with TMZ combined with BC3EE2,9B for $24 \mathrm{~h}$, followed by acridine orange staining. Formation of acridine orange-accumulating autophagic vacuoles (orange-red fluorescence) in cells treated with BC3EE2,9B and TMZ. (C) Cells stained with 4',6-diamidino-2-phenylindole (DAPI) and green fluorescent anti-LC3-II. The images show that cells treated with TMZ combined with BC3EE2,9B have significant LC3-II aggregation.

enhances autophagy through inactivation of the Akt-mTOR pathway, western blot assays using specific antibodies were performed. BC3EE2,9B combined with TMZ resulted in a significant decrease in Akt and mTOR phosphorylation, as well as a significant increase in AMPK phosphorylation after $24 \mathrm{~h}$ (Fig. 6B), suggesting that BC3EE2,9B/TMZ-induced autophagy may involve activation of AMPK and the attenuation of the Akt and mTOR downstream signaling pathway. To further confirm whether the inactivation of the Akt pathway is essential for combination treatment-induced autophagy, constitutively active Akt (CA-Akt) or dominant negative Akt (DN-Akt) plasmids were transfected into GBM8901 cells. The two plasmids were successfully transfected and expressed in glioblastoma cells (Fig. 6C). The cells were subsequently treated with BC3EE2,9B combined with TMZ to observe the treatment effect on cell viability. The results showed that the DN-Akt significantly protected against cytotoxicity of BC3EE2,9B combined with TMZ treatments
(21.76\%) (Fig. 6D). These results indicate that BC3EE2,9B combined with TMZ induces autophagic cell death via the AKT-mTOR pathway in GBM8901 cells.

\section{Discussion}

GBM is one of the most treated refractory tumors. Standard therapy for GBM includes surgical resection, focal radiotherapy and treatment with the alkylating agent TMZ. However, this therapeutic approach results in only a modest increase in survival of patients with the disease. Novel therapeutic approaches aimed at improving the efficacy of TMZ are, therefore, urgently required. The present study identified that treatment with the carbazole derivative, BC3EE2,9B, resulted in a marked decrease in cell viability, migration and invasion in GBM8901 glioblastoma cells, but not in Detroit 551 normal cells. Furthermore, combination treatment with BC3EE2,9B and TMZ inhibited glioblastoma growth to a much higher 


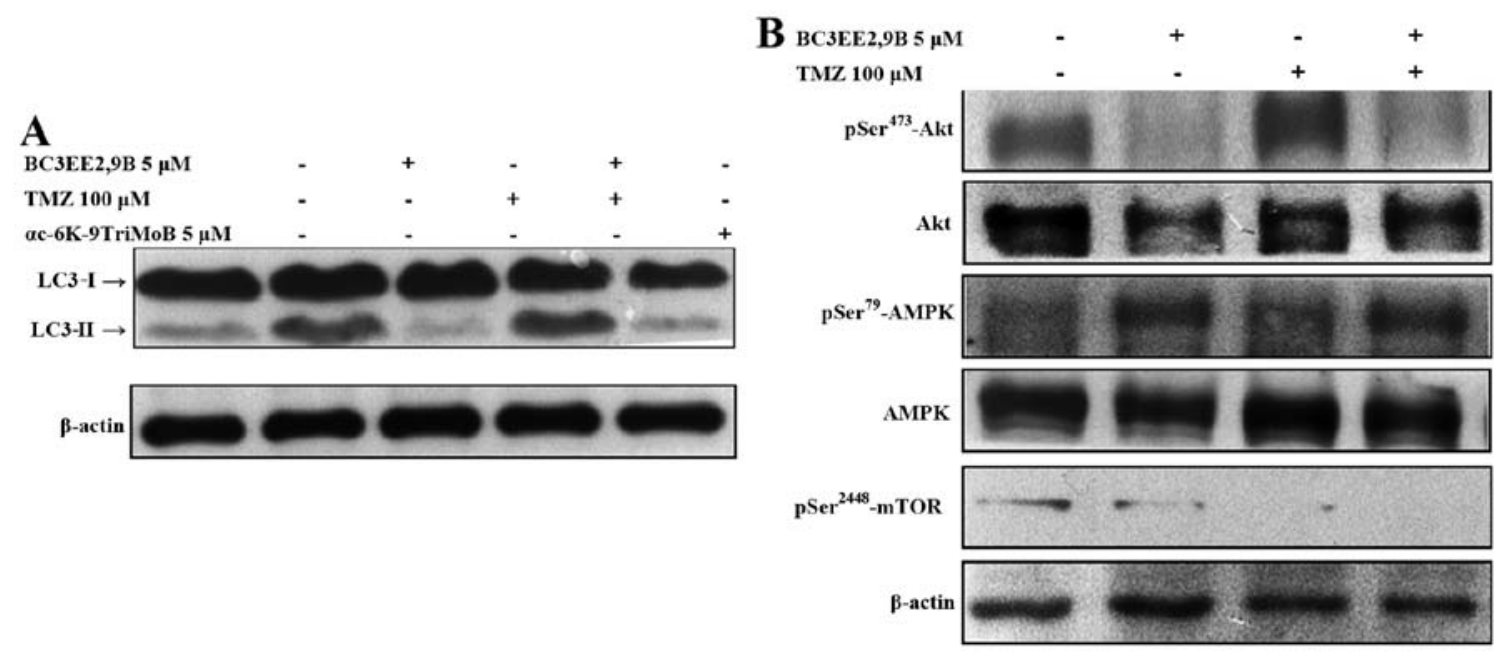

C

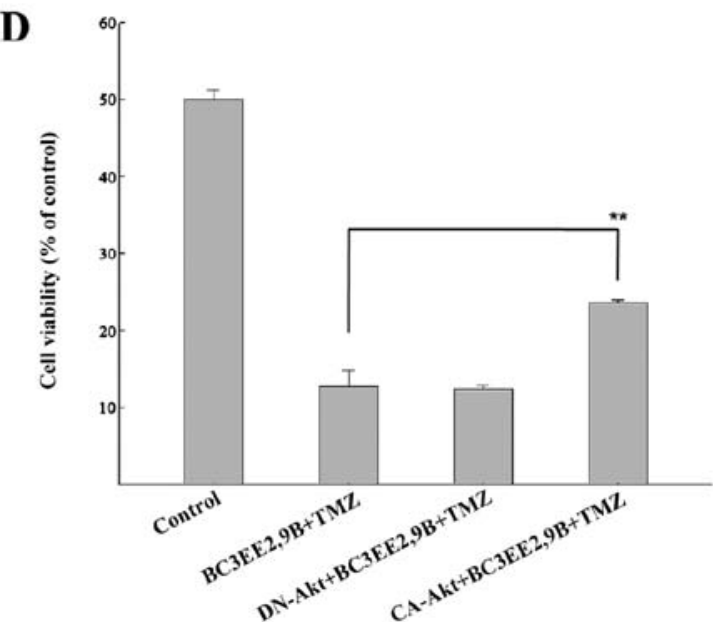

Figure 6. Induction of autophagy in glioblastoma multiforme (GBM)8901 cells treated with bis(carbazole-2,9N-benzyl)-3-ethyl ethanoate (BC3EE2,9B) combined with temozolomide (TMZ) is governed by the Akt-mammalian target of rapamycin (mTOR) pathway. (A) Monitoring of LC3-I to LC3-II conversion in western blot analysis shows autophagy induction. BC3EE2,9B combined with TMZ resulted in a significant increase in the levels of LC3-II after 24 $\mathrm{h}$. (B) Western blot analysis showed p-Akt/Akt, p-AMPK/AMPK and p-mTOR expression in GBM8901 cells treated with BC3EE2,9B alone or treated with BC3EE2,9B in combination with TMZ $(100 \mu \mathrm{M})$. (C) Constitutively active Akt (CA-Akt) or dominant negative Akt (DN-Akt) plasmids were transiently transfected into GBM8901 cells and confirmed by western blot analysis. (D) Overexpression of CA-Akt but DN-Akt was noted in GBM8901 cells treated with BC3EE2,9B combined with TMZ.

extent compared with the treatment with TMZ or BC3EE2,9B alone. In addition, co-administration of BC3EE2,9B and TMZ significantly enhanced autophagic death, most likely through inhibition of the Akt-mTOR signaling pathway. This supports the idea that BC3EE2,9B synergistically sensitizes glioblastoma cells to TMZ-induced cytotoxicity. Acquired drug resistance is associated with TMZ treatment in GBM patients. The results indicate that combination therapy, comprising a toxic chemotherapeutic agent (TMZ) with a nontoxic naturally occurring compound that has anticancer properties (BC3EE2,9B) could be a new strategy to overcome this problem.

Glioblastoma cells frequently carry mutations in the PTEN tumor-suppressor gene, a gene that inhibits the continuous activation of Akt (3), making them relatively resistant to TMZ treatment (4). As mutations in glioblastoma cells often inactivate the apoptotic pathway, they are likely to be more sensitive to autophagy as an alternative response to therapeutic agents (23). Furthermore, agents that induce autophagy may result in fewer side effects than those that induce apoptosis, as apoptotic bodies are removed by phagocytic cells, thus preventing an inflammatory response $(9,10)$. Carbazole derivatives have been shown to act as inhibitors of DNA topoisomerase and exert their cytotoxic effects in replicating cells by interfering with DNA repair and inducing DNA strand breaks (24). $\mathrm{O}^{6}$-methylguanine-DNA methyltransferase (MGMT), a DNA repair protein that removes $\mathrm{O}^{6}$-methylguanine adducts from damaged DNA, is the most important determinant of TMZ resistance in patients with GBM. As a result, proficient DNA repair activities promote glioblastoma cell survival, leading to TMZ resistance and poor clinical outcome. These observations support the present findings that although glioblastoma cells treated with TMZ alone failed to show significant autophagy, TMZ combined with BC3EE2,9B treatment inhibited Akt-mTOR signaling enhanced sensitivity of these cells by increasing the extent of autophagy and appeared to synergistically promote cell death. The autophagic effect of carbazole derivatives provides insight into the anticancer activities of this compound, particularly in TMZ-resistant and apoptosis-resistant glioblastoma cells.

AMPK is a sensor of energy status. Although it is best known for its effects on metabolism, AMPK is involved in 
numerous important pathways that govern a variety of physiological activities including cell growth, survival, migration and cell-cycle regulation (25). Recent studies have shown that the activation of the AMPK pathway is associated with autophagy in cancer cells (26). In the present study, BC3EE2,9B treatment decreased the phosphorylation of Akt and activated AMPK. In fact, various active compounds isolated from natural products are effective in inducing autophagic cell death in apoptosis-resistance cells. For example, ursolic acid has been shown to induce cell death and modulate autophagy in apoptosis-resistant colorectal cancer cells (27). Additionally, coibamide A, a potent antiproliferative cyclic depsipeptide isolated from a marine cyanobacterium, has been shown to induce autophagic cell death in apoptosis-resistant glioblastoma cells (28). Therefore, a number of autophagy-inducing carbazole compounds that can activate autophagic cell death independent of the apoptotic process were synthesized in the present study. These results point to a potential therapeutic role of alkaloids in apoptosis-resistant cancers, such as TMZ-treated glioblastoma cells.

In the present study, BC3EE2,9B, a carbazole derivative, was demonstrated to inhibit glioblastoma cell migration, invasion and growth. The data also indicate that BC3EE2,9B induced autophagy-mediated cell death and synergistically sensitized GBM cells to TMZ cytotoxicity. The possible mechanism underlying BC3EE2,9B-induced autophagy may involve activation of AMPK and the attenuation of the Akt and mTOR downstream signaling pathway. Taken together, the data provide molecular evidence for the mode of action governing the ability of BC3EE2,9B to sensitize drug-resistant glioblastoma cells to the chemotherapeutic agent TMZ.

\section{Acknowledgements}

The present study was supported by grants from the Changhua Christian Hospital (no. 103-CCH-IRP-025) and from the Ministry of Science and Technology (no. 101-2320-B-040-015-MY3). Fluorescence microscopy and imaging analysis were performed at the Instrument Center of the Chung Shan Medical University, which is supported by the Ministry of Science and Technology, Ministry of Education and the Chung Shan Medical University.

\section{References}

1. Hess KR, Broglio KR and Bondy ML: Adult glioma incidence trends in the United States, 1977-2000. Cancer 101: 2293-2299, 2004.

2. Adamson C, Kanu OO, Mehta AI, Di C, Lin N, Mattox AK and Bigner DD: Glioblastoma multiforme: A review of where we have been and where we are going. Expert Opin Investig Drugs 18: 1061-1083, 2009.

3. Omuro A and DeAngelis LM: Glioblastoma and other malignant gliomas: A clinical review. JAMA 310: 1842-1850, 2013.

4. Roos WP, Batista LF, Naumann SC, Wick W, Weller M, Menck CF and Kaina B: Apoptosis in malignant glioma cells triggered by the temozolomide-induced DNA lesion $\mathrm{O}^{6}$-methylguanine. Oncogene 26: 186-197, 2007

5. Brandes AA, Tosoni A, Franceschi E, Sotti G, Frezza G, Amistà P, Morandi L, Spagnolli F and Ermani M: Recurrence pattern after temozolomide concomitant with and adjuvant to radiotherapy in newly diagnosed patients with glioblastoma: Correlation with MGMT promoter methylation status. J Clin Oncol 27: 1275-1279, 2009.
6. Murrow L and Debnath J: Autophagy as a stress-response and quality-control mechanism: Implications for cell injury and human disease. Annu Rev Pathol 8: 105-137, 2013.

7. Shen HM and Codogno P: Autophagic cell death: Loch Ness monster or endangered species? Autophagy 7: 457-465, 2011.

8. Lefranc F, Facchini V and Kiss R: Proautophagic drugs: A novel means to combat apoptosis-resistant cancers, with a special emphasis on glioblastomas. Oncologist 12: 1395-1403, 2007.

9. Edinger AL and Thompson CB: Death by design: Apoptosis, necrosis and autophagy. Curr Opin Cell Biol 16: 663-669, 2004.

10. Chen $\mathrm{N}$ and Karantza-Wadsworth V: Role and regulation of autophagy in cancer. Biochim Biophys Acta 1793: 1516-1523, 2009.

11. Chen C, Chen J and Zhao KN: Editorial: Signalling pathways in anti-cancer drug resistance. Curr Med Chem 21: 3007-3008, 2014.

12. Mathew R, Karantza-Wadsworth V and White E: Role of autophagy in cancer. Nat Rev Cancer 7: 961-967, 2007.

13. Zeng $X$ and Kinsella TJ: A novel role for DNA mismatch repair and the autophagic processing of chemotherapy drugs in human tumor cells. Autophagy 3: 368-370, 2007.

14. Kanzawa T, Germano IM, Komata T, Ito H, Kondo Y and Kondo S: Role of autophagy in temozolomide-induced cytotoxicity for malignant glioma cells. Cell Death Differ 11: 448-457, 2004.

15. Math $\mathrm{M}$ and Balasubramaniam P: Curry leaves (Murraya Koenigii spreng) and halitosis. BMJ (South Asia ED) 19: 211, 2003.

16. Tsao LT, Lee CY, Huang LJ, Kuo SC and Wang JP: Inhibition of lipopolysaccharide-stimulated nitric oxide production in RAW 264.7 macrophages by a synthetic carbazole, LCY-2-CHO. Biochem Pharmacol 63: 1961-1968, 2002.

17. Arbiser JL, Govindarajan B, Battle TE, Lynch R, Frank DA, Ushio-Fukai M, Perry BN, Stern DF, Bowden GT, Liu A, et al: Carbazole is a naturally occurring inhibitor of angiogenesis and inflammation isolated from antipsoriatic coal tar. J Invest Dermatol 126: 1396-1402, 2006.

18. Hajbi Y, Neagoie C, Biannic B, Chilloux A, Vedrenne E, Baldeyrou B, Bailly C, Mérour JY, Rosca S, Routier S, et al: Synthesis and biological activities of new furo[3,4-b]carbazoles: Potential topoisomerase II inhibitors. Eur J Med Chem 45: 5428-5437, 2010

19. Yoon S, Kim JH, Lee YJ, Ahn MY, Choi G, Kim WK, Yang Z, Lee HJ, Moon HR and Kim HS: A novel carbazole derivative, MHY407, sensitizes cancer cells to doxorubicin-, etoposide-, and radiation treatment via DNA damage. Eur J Pharmacol 697: 24-31, 2012.

20. Liu CH, Lin C, Tsai KJ, Chuang YC, Huang YL, Lee TH, Huang LJ and Chan HC: Biological evaluation of 9-[(6-chloropyridin-4-yl)methyl]-9H-carbazole-3-carbinol as an anticancer agent. Oncol Rep 29: 1501-1509, 2013.

21. Kang CC, Huang WC, Kouh CW, et al: Chemical principles for the design of a novel fluorescent probe with high cancer-targeting selectivity and sensitivity. Integr Biol 5: 1217-1228, 2013.

22. Mizushima N and Yoshimori T: How to interpret LC3 immunoblotting. Autophagy 3: 542-545, 2007.

23. Gozuacik D and Kimchi A: Autophagy as a cell death and tumor suppressor mechanism. Oncogene 23: 2891-2906, 2004.

24. Zembower DE, Xie Y, Koohang A, Kuffel MJ, Ames MM,Zhou Y, Mishra R, Mar AA, Flavin MT and Xu ZQ: Methylenedioxy- and ethylenedioxy-fused indolocarbazoles: Potent human topoisomerase I inhibitors and antitumor agents. Anticancer Agents Med Chem 12: 1117-1131, 2012.

25. Lee YK, Park SY, Kim YM, Kim DC, Lee WS, Surh YJ and Park OJ: Suppression of mTOR via Akt-dependent and -independent mechanisms in selenium-treated colon cancer cells: Involvement of AMPKalpha1. Carcinogenesis 31: 1092-1099, 2010.

26. Puissant A, Robert G, Fenouille N, Luciano F, Cassuto JP, Raynaud $\mathrm{S}$ and Auberger P: Resveratrol promotes autophagic cell death in chronic myelogenous leukemia cells via JNK-mediated p62/SQSTM1 expression and AMPK activation. Cancer Res 70: 1042-1052, 2010.

27. Xavier CP, Lima CF, Pedro DF, Wilson JM, Kristiansen K and Pereira-Wilson C: Ursolic acid induces cell death and modulates autophagy through JNK pathway in apoptosis-resistant colorectal cancer cells. J Nutr Biochem 24: 706-712, 2013.

28. Hau AM, Greenwood JA, Löhr CV, Serrill JD, Proteau PJ, Ganley IG, McPhail KL and Ishmael JE: Coibamide A induces mTOR-independent autophagy and cell death in human glioblastoma cells. PLoS One 8: e65250, 2013. 